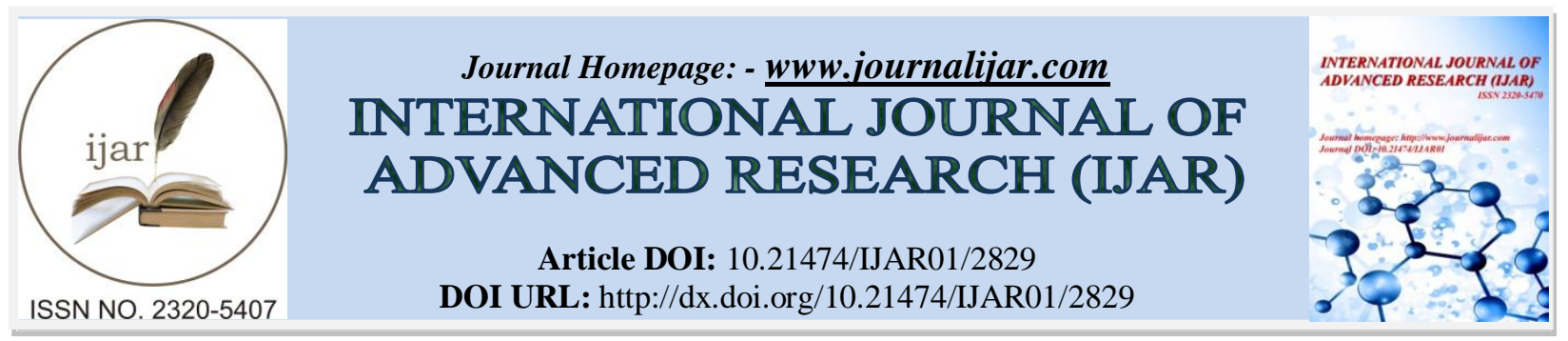

RESEARCH ARTICLE

\title{
SYNTHESIS AND STRUCTURAL PROPERTIES OF ZnO NANOPARTICLES BY ALTERNANTHERA SESSILE LEAVES EXTRACT.
}

\author{
S. Sai Ganesh ${ }^{1}$, S.Rajesh ${ }^{1}$ and Dr.K.Thyagarajan ${ }^{2}$, \\ 1. Research Scholar, Department of Physics, JNTU Ananthapur, Andhra Pradesh, India. \\ 2. Head\& Associate Professor, Department of Physics, JNTUA College of Engineering, Pulivendula- \\ 516930, Y.S.R.District, Andhra Pradesh, India
}

\section{Manuscript Info}

Manuscript History

Received: 18 November 2016

Final Accepted: 19 December 2016

Published: January 2017

Key words:-

$\mathrm{ZnO}$ nanoparticle, Green synthesis, capping and reducing agent, Alternanthera Sessile

\section{Abstract}

Green synthesis is environmentally friendly technique for synthesis of metal Oxide nanoparticles.In this present work, synthesis of $\mathrm{ZnO}$ nanoparticles were prepared by Green Synthesis method. Here Leaf extract of Alternanthera Sessile can be used as reducing and capping agent for synthesis of stabilized $\mathrm{ZnO}$ nanoparticles . $\mathrm{ZnO}$ nanoparticles were characterized by $\mathrm{X}$ - ray diffraction (XRD), Scanning Electron Microscope (SEM), Energy dispersive analysis of X-rays (EDAX)and Fourier transform infrared spectroscopy (FTIR).From X-ray diffraction studies it is observed that (101) phase obtained at $36.68^{0} 2$ theta value. The size of the nanoparticle is $22 \mathrm{~nm}$ at this peak.It was observed that the shape of the $\mathrm{ZnO}$ particles is agglomerated spherical by SEM attached with EDS analysis. From FTIR analysis, it was observed that Alkenes and Nitriles functional groups in this leaf extract used as reducing agent for synthesis of $\mathrm{ZnO}$ nanoparticles. It was proved by peaks were obtained at wave numbers $809 \mathrm{~cm}^{-1}, 909 \mathrm{~cm}^{-1}, 2331 \mathrm{~cm}^{-1}$ and $2361 \mathrm{~cm}^{-1}$.

Copy Right, IJAR, 2016,. All rights reserved.

\section{Introduction:-}

$\mathrm{ZnO}$ is one of the most promising materials for analyse optical and electrical properties. The superiority of $\mathrm{ZnO}$ photocatalytic activity and semiconductor property because it is direct band gap semiconductor of, bandgap of 3.37 $\mathrm{eV} . \mathrm{ZnO}$ has a wide range of applications in optoelectronic devices such as light-emitting diodes, photodetectors, and p-n homojunctions lasers. $\mathrm{ZnO}$ has higher luminescence efficiency of the emitted light even at room temperature. Many techniques including chemical vapor deposition, pulsed laser deposition, molecular beam epitaxy, sputtering, hydrothermal synthesis, and oxidation of metallic zinc powder have been used to prepare $\mathrm{ZnO}$ in different forms and structures for various applications. Nanoparticulate form enhances the catalytic activity due to its large surface area and the presence of vacancies and uncoordinated atoms at corners and edges. The photocatalytic activity is also improved by bandgap engineering, as a result of the quantum confinement effect. A well-controlled synthesis process at room temperature is needed for the economical use of $\mathrm{ZnO}$ in catalytic applications such as water treatment and other environmental applications. Plant crude contains novel secondary metabolites such as phenolic acid,flavonoids, alkaloids and terpenoids in which these compounds are mainly responsible for the reduction of ionic into bulk Metallic nanoparticles formation.Plant metabolites involved in the bioreduction i.e Amine,Nitrile,Carboxyl and Alkene group in the Leaf extract of Alternanthera Sessile which one responsible for reducing ionic compounds into Metal oxide nanoparticles.Nano particles synthesised by green synthesis method, can be used for Anti oxidant 
and antimicrobial activity.From biological approach using leaf extract of Alternanthera Sessile has been used for the first time as a reducing material as well as surface stabilizing agent for the synthesis of spherical-shaped ZnO-NPs. The structure, phase, and morphology of synthesized product were investigated by the standard characterization techniques.

\section{Experimental:- \\ Synthesis of ZnO-NPs:-}

Zinc acetate dihydrate and glassware was purchased from Indian scientific company, tirupati. All glassware was washed with sterile distilled water and dried in an oven before use.

$\mathrm{ZnO}$ NPs can be synthesized by using the leaves extract of plant Alternanthera sessile. In this procedure, $600 \mathrm{ml}$ of distilled water is taken and aqueous zinc acetate dihydrate is added into it under constant stirring and make it $0.1 \mathrm{M}$ solution.Then after $10 \mathrm{~min}$ stirring the aqueous leaf extract of Alternanthera sessile is introduced into the above solution. $2 \mathrm{M} \mathrm{NaOH}$ is also added to make $\mathrm{pH} 12$ resulting in a pale white aqueous solution.It is then placed in a magnetic stirrer for 2 hrs. After stirring, pale white precipitate is centrifuged and washed many times with distilled water followed by ethanol to make it free from impurities. Then after drying in vacuum oven overnight, a pale white powder of $\mathrm{ZnO}$ nanoparticles will be obtained at $100^{\circ} \mathrm{C}$ temperature.

\section{Chemical reaction formula:-}

1. $\mathrm{Zn}\left(\mathrm{CH}_{3} \mathrm{COOH}\right) .2 \mathrm{H} \mathrm{O}+\mathrm{NaOH}+$ leaf extract $\rightarrow \mathrm{Zn}(\mathrm{OH}) \underset{2}{\downarrow} \underset{2}{\downarrow}+2 \mathrm{CH} \mathrm{COOH}+\mathrm{NaOH}$

2. $\mathrm{Zn}(\mathrm{OH})_{2}^{3} \rightarrow \underset{2}{2} \underset{2}{2} \stackrel{2}{\mathrm{O}} \uparrow$

\section{Result and Discussions:-}

From X-Ray Diffraction (XRD) Analysis of The ZnONp powdered sample was examined by a CuKa1- X Ray Diffractometer for confirming the presence of $\mathrm{ZnO}$ and its structure. Main peaks corresponding to $2 \theta$ values of $32.14^{\circ}, 34.83^{\circ}, 36.68^{\circ}, 47.98^{\circ}, 56.91^{\circ}, 63.32^{\circ}, 68.38^{\circ}, 69.58^{\circ}, 77.40^{\circ}, 90.07^{\circ}$ and $95.86^{\circ}$ in the multi-plot have observed from the graph as shown in Fig. The observed peaks of the graph are in good agreement with the JCPDS data card no:36-1451,proved that ZnO NPs has Wurzite structure. Peaks was compared to standard literature values and the presence of zinc oxide particles was confirmed. The average size of the particles was calculated as $22 \mathrm{~nm}$ using Debye-Scherrer's formula:

where $\mathrm{k}$ is Scherer constant $=0.9$.

$$
D=\frac{k \times \lambda}{\beta_{h k l} \times \cos \theta}
$$

the wave length of the source $\lambda=15.406 \mathrm{~nm}$.

Lattice parameters are calculated from the following equations $a=\frac{\lambda}{\sqrt{3} \sin \theta_{100}}$

$$
\begin{aligned}
c & =\frac{\lambda}{\sin \theta_{002}} \\
V & =\frac{\sqrt{3} a^{2} c}{2} \\
\text { Interplanar spacing } d_{h k l} & =\frac{1}{\sqrt{\frac{4\left(\frac{h^{2}+k^{2}+h k}{a^{2}}\right)}{3}+\frac{l^{2}}{c^{2}}}}
\end{aligned}
$$




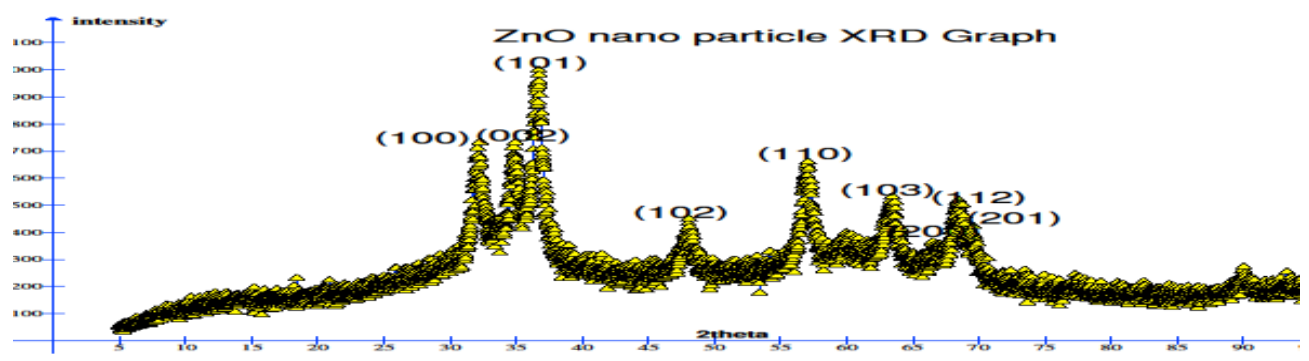

Fig 1:- XRD graph of Alternanthera Sessile leaves $\mathrm{ZnO}$ nanoparticles

Table 1:- The structural parameters of Alternanthera Sessile leaves $\mathrm{ZnO}$ nanoparticles

\begin{tabular}{|l|l|l|l|l|l|l|}
\hline data & $2 \theta$ & $\mathrm{hkl}$ & $\mathrm{d}_{\mathrm{hkl}}(\AA)$ & Structure & $\begin{array}{l}\text { Lattice } \\
\text { parameters }(\AA)\end{array}$ & $\left.\mathrm{V}^{(} \AA^{3}\right)$ \\
\hline sample & 32.14 & $(100)$ & 2.783 & Hexagonal & $\begin{array}{l}\mathrm{a}=3.213 \\
\mathrm{c}=5.152 \\
\mathrm{c} / \mathrm{a}=1.6035\end{array}$ & 46.05 \\
& 34.83 & $(002)$ & 2.582 & & $\begin{array}{l}\mathrm{a}=3.250 \\
\mathrm{c}=5.207 \\
\mathrm{c} / \mathrm{a}=1.6021\end{array}$ & 47.63 \\
\hline $\begin{array}{l}\text { Jcpds(36- } \\
1451)\end{array}$ & 31.770 & $(100)$ & 2.814 & Hexagonal & & \\
\hline
\end{tabular}

\section{SEM \&EDAX analysis:}

From the SEM analysis observed that $\mathrm{ZnO}$ nanoparticles were agglomerated spherical in shape.In reported journal they have stated that agglomerated spherical Shape $\mathrm{ZnO}$ nanoparticles formed by Green synthesis method.The particle size roughly estimated as $15-30 \mathrm{~nm}$ from SEM analysis.

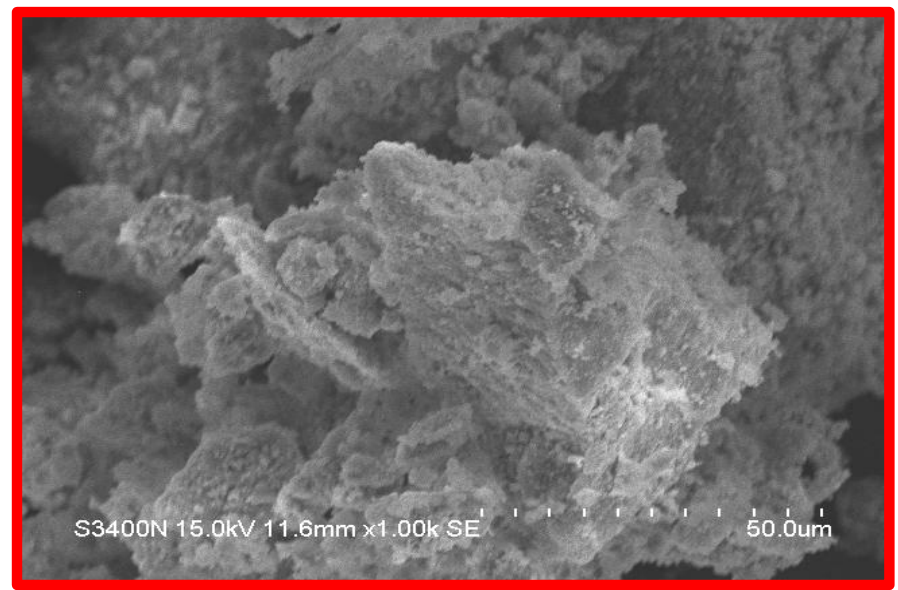

Fig 2:- SEM image of Alternanthera Sessile leaves-ZnO nanoparticles

EDAX: The sample contains only Zinc and Oxygen and no other impurity are present in the sample. This was conformed by the EDAX study. 


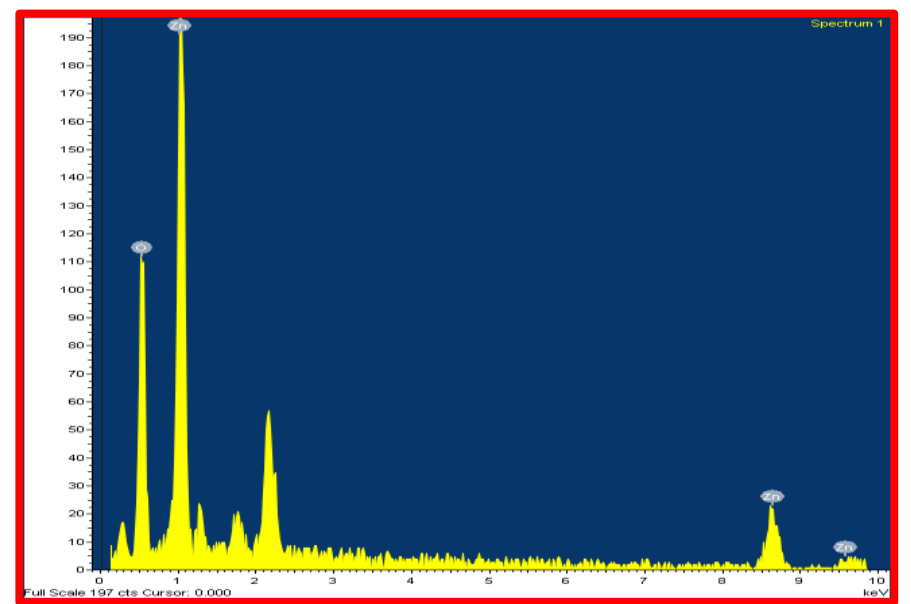

Fig 3:- EDAX graph of $\mathrm{ZnO}$ nanoparticles of Alternanthera Sessile leaves

Table-2:AtomicWeight percentage of Alternanthera Sessile leaves $\mathrm{ZnO}$ nanoparticles from EDAX graph

\begin{tabular}{|l|l|l|}
\hline tnemelE & egatnecrep thgieW & egatnecrep cimotA \\
\hline $\mathrm{K} \mathrm{O}$ & 35.76 & 69.46 \\
\hline $\mathrm{K} \mathrm{nZ}$ & 64.24 & 30.54 \\
\hline Total & 100 & 100 \\
\hline
\end{tabular}

Fourier Transform Infrared Spectroscopy (FTIR):-

The FTIR spectrum of $\mathrm{ZnO}$ nanoparticles is shown in Figure . For the IR spectra of unannealed samples (Fig-4), a series of transmission peaks from 500 to $4000 \mathrm{~cm}-1$ can be found, corresponding to the carboxylate and hydroxyl impurities in materials. The $\mathrm{O}-\mathrm{H}$ stretching mode of hydroxyl group has confirmed by peaks observing at 3501 and $1206 \mathrm{~cm}-1$ wave numbers due to water adsorption by $\mathrm{ZnO}$ nanoparticles. The peaks assigned at 1630 and $1384 \mathrm{~cm}-1$ are due to the asymmetrical and symmetrical stretching of the zinc carboxylate, respectively. As the size of the nanoparticles increases, the content of the carboxylate (COO-) and hy-droxyl (-OH) groups in the samples decreased. The hygroscopic nature of $\mathrm{ZnO}$ causes to form zinc carboxylate and zinc hy-droxyde .

The fundamental mode of vibration at $1647 \mathrm{~cm}-1$ which correspond to the $\mathrm{C}=\mathrm{O}$ stretching vibration, $3396 \mathrm{~cm}-1$ which correspond to the $\mathrm{N}-\mathrm{H}$ bend, $1556 \mathrm{~cm}-1$ which corresponds to $\mathrm{N}=\mathrm{O}$ stretching vibration were confirmed Amide group present in Alternanthera Sessile leaves. Peaks at 909 and $809 \mathrm{~cm}-1$ which correspond to O-H bend,2331 and $2361 \mathrm{~cm}-1$ which correspond to $\mathrm{C} \equiv \mathrm{N}$ stretch were conformed that carboxylic acid ,Alkenes and Nitriles present in the Alternanthera Sessile leaves. Amides, carboxylic acid, Alkenes and Nitriles groups in this leaves serves as the reducing agents for minimal of particle size becomes few nano meters.

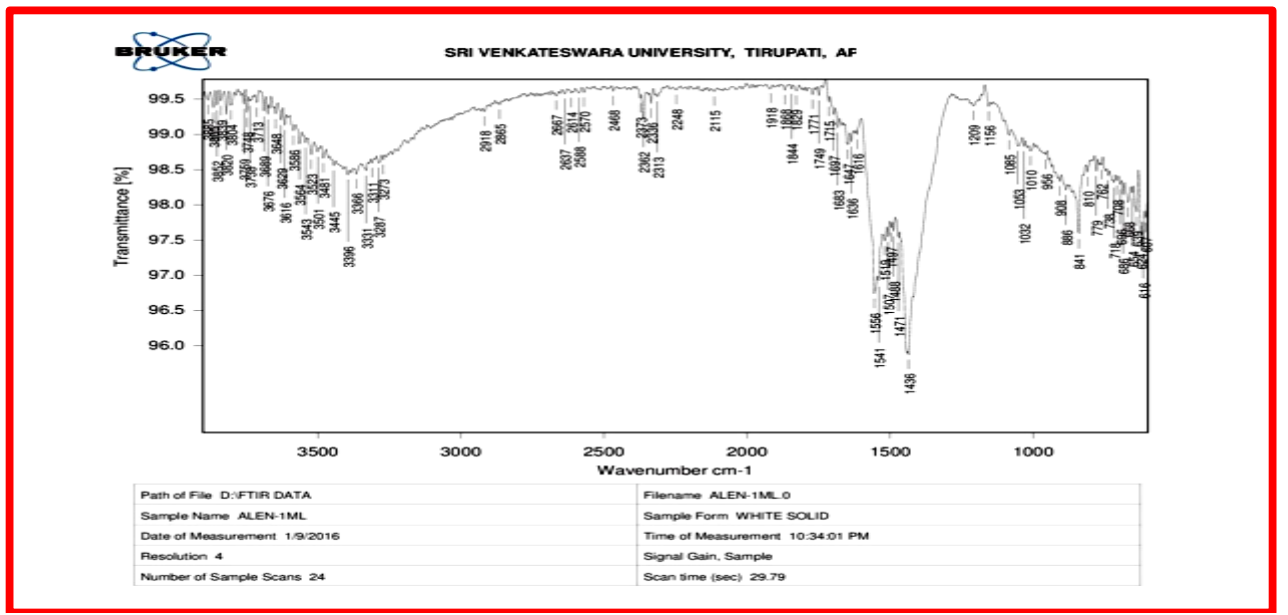

Fig 4:- FTIR graph of $\mathrm{ZnO}$ nanoparticles of Alternanthera Sessile leaves. 


\section{Conclusions:-}

The Green synthesis of zinc oxide nanoparticles using leaf extract of Alternanthera Sessile provides anenvironmental friendly, easy and effective route for synthesis of nanoparticles.From the use of plant extracts eliminates bad effects from the usage of harmful and toxic reducing and stabilizing agents. The nano crystallites of $\mathrm{ZnO}$ are in the range of $18-30 \mathrm{~nm}$. The operating temperature and $\mathrm{P}^{\mathrm{H}}$ of the solution will affect thestability of nano particle and agglomerates are formed.The Green synthesis of $\mathrm{ZnO}$ nano particles is still in its Research progress for focusing in the fields of pharma,optical energy conversion and spintronics by tuning its size over few nanometers.

\section{Reference:-}

1. "Green Synthesis of Zinc Oxide (ZnO) Nanoparticles Using OcimumTenuiflorum Leaves"-Sagar Raut, Dr. P. V. Thorat, RohiniThakre-International Journal of Science and Research (IJSR)-Volume 4 Issue 5, May 2015,page no-1225-1228.

2. "Green synthesis, characterization and optical properties of zinc oxide nanosheets using Olea europealeaf extract"-Akl M. Awwad*, BorhanAlbiss, Ahmad L. Ahmad-Adv. Mat. Lett. 2014, 5(9), 520-524 .

3. "X-ray Peak Broadening Analysis of ZnO Nanoparticles Derived by Precipitation method"-Hiten Sarma*, K.C. Sarma-International Journal of Scientific and Research Publications, Volume 4, Issue 3, March 2014 1,page no-1 - 7.

4. NadiafebianaDjaja,RosariSaleh," characteristics and photocatalytics activities of Ce-Doped ZnO Nanoparticles "Materials sciences and applications, vol4,145-152,2013. [5] N. Duran, P.D. Marcato, O.L. Alves, G. Souza, J. Nanotechnol. 3 (2005) 1-7.

5. Riteshkumar,Induvarma,NidhiVerma,"synthysis and characterization of Mn doped $\mathrm{ZnO}$ particles prepared by a co-precipitation method", international journal of advanced technology \&engineering research,vol2, issue3, may 2012.

6. George Varughese,K.T.usha,,A.S.kumar,"zinc sulfide nonmaterial doped with rare earth Neodymium-an optical study"international journal of engineering science and innovative technology,vol3, issue4,july2014

7. RadhouaneBel-Hadj-tahar,AbdellatifBelhadjmohamed"sol-gel processed Indium -doped zinc Oxide ThinFIlms and their elecrical and optical properties"new journal of glass and ceramics,vol4, 55-65,2014.

8. Nitinpandey,Rajneeshkumarsrivastava\&S.G.prakash"study of photoelectret effect in dysprosium doped zinc oxide" indian journal of pure \&applied physics, vol50,260-264, april2012.

9. KhalidT.Al-Rasoul,Nadak.Abbas,Zainb J.Shanan,"structural and optical characterization of $\mathrm{Cu}$ and $\mathrm{Ni}$ doped ZnS Nanoparticles", international journalof electrochemicalscience,vol8,5594-5604,2013.

10. Bappadityapal ,soumendhara, P.K. Giri , D. Sarkar"Room temperature ferromagnetism with high magnetic moment and optical properties of Co doped ZnOnano rods synthesized by a solvothermal route". Journal of alloys and compounds, vol-615, pages -378-385,2014

11. Ratulkumardas,NayanmoniGogoi,PunuriJayasekharBabu, Pragya Sharma ChandanMahanta, Utpal Bora, "The synthesis of Gold Nanoparticles UsingAmaranthusSpinous Leaf Extract and Study of their Optical Properties."Advances in materials and chemistry,2012,2,275-281.

12. NiranjanBala, S.Saha,M.Chakraborty,M.Maiti,S.Das,R.Basu and P.Nandy "Green synthesis of zinc oxide nanoparticles using Hibiscus subdariffa leaf extract :effect of temperature on synthesis, anti-bacterial activity and anti-diabetic activity",5,2015,4993-5003 